\title{
FIGURAÇÕES DE JOVENS NO ENSINO MÉDIO: TRAÇANDO ELEMENTOS DE UM JOGO SOCIOCULTURAL
}

\author{
CONFIGURATION OF YOUNG PEOPLE IN HIGH SCHOOL: \\ TRACING ELEMENTS OF A SOCIOCULTURAL GAME
}

\author{
FIGURACIONES DE LOS JÓVENES EN LA ESCUELA \\ SECUNDÁRIA: TRAZAR ELEMENTOS \\ DE UN JUEGO SOCIOCULTURAL
}

\author{
Samuel Pires Melo ${ }^{\mathrm{I}}$ \\ Jullyane FrazÃo SANTANA ${ }^{\mathrm{I}}$ \\ Thaís CaRvalho dos SANTOS ${ }^{\mathrm{I}}$
}

\begin{abstract}
Resumo O objetivo deste artigo é analisar as teias de interação de jovens com escolas do ensino médio da cidade de Parnaíba, Estado do Piauí. Esses grupos sociais que se constituem em teias de inter-relações que ultrapassam uma figuração central, podendo observar várias intra e inter figurações firmadas por processos identitários de afirmação, conflitos e indagações diante de outras figurações, possibilitam mostrar elementos essenciais dos jogos socioculturais de um processo social. Para analisar esses elementos, utilizou-se de uma abordagem tipo quantitativo, com as técnicas de construção das informações o diário de campo e questionário. E foram tratados por meio da planilha do software Statistical Packege for Social Sciences (SPSS). As figurações que se destacaram nesses jogos foram: família, escola, amizade, lazer, trabalho e Tecnologias Digitais. No entanto, vale salientar, que ora existe uma complementaridade e/ou afastamento entre elas, mas que são importantes no processo de afirmação das condições juvenis.
\end{abstract}

Palavras-chave: FiguraÇões Sociais; Juventudes; Ensino Médio; Socioculturais.

Abstract The objective of this article is to analyze the interaction webs of young people with high school in the city of Parnaíba, state of Piauí. These social groups, which constitute interconnected webs that go beyond a central figuration, and can observe several intra and inter-figurations, established by identity processes of affirmation, conflicts, and inqui-

${ }^{1}$ Universidade Federal do Piauí

Comunicações | Piracicaba | v. 25 | n. 1 | p. 143-161| janeiro-abril 2018143 
ries with other figurations, make it possible to show essential elements of the sociocultural plays of a process social. To analyze these elements, a quantitative type approach was used, with the construction techniques of the information field diary and questionnaire. In addition, they were treated through the Statistical Package for Social Sciences software (SPSS) spreadsheet. The figurations that stood out in these games were: family, school, friendship, leisure, work and Digital Technologies. However, it is worth emphasizing that there is a complementarity and / or distance between them, but they are important in the process of affirming the conditions of the youth.

KeY-words: Social Figurations; Youths; High School; Sociocultural.

RESUMen El objetivo de este artículo es analizar las redes de interacción de jóvenes de las escuelas secundárias de la ciudad de Parnaíba, estado de Piauí. Los grupos sociales que se constituyen en las redes de interrelaciones que sobrepasan una figuración central, pudiendo observar varias intra e inter-figuraciones firmadas por procesos identitarios de afirmación, conflictos e indagaciones ante otras figuraciones, posibilitan mostrar elementos esenciales de los juegos socioculturales de un proceso Social. Para analizar estos elementos, se utilizó un enfoque tipo cuantitativo, con las técnicas de construcción de las informaciones el diario de campo y el cuestionario. Y fueron tratados a través de la hoja de cálculo del software Statistical Packege for Social Sciences (SPSS). Las figuras que se destacaron en estos juegos fueron: familia, escuela, amistad, ocio, trabajo y Tecnologías Digitales. Sin embargo, cabe subrayar, que ahora existe una complementariedad y / o alejamiento entre ellas, pero que son importantes en el proceso de afirmación de las condiciones juveniles.

Palabras clave: Figuraciones sociales; Juventudes; Escuelas secundárias; SociocultuRALES.

\section{INTRODUÇÃo}

O presente trabalho focalizará o levantamento de informações que evidenciem os jogos socioculturais de jovens com escolas do ensino médio da cidade de Parnaíba-PI, por meio de teias de inter-relações que ultrapassam uma figuração central, podendo observar várias figurações específicas, firmadas por condições juvenis identitárias de afirmação, conflitos e indagações diante de outras figurações, possibilitando mostrar elementos essenciais de um processo social.

Ao propor essa discussão, entendemos que as condições juvenis no Brasil são construídas pelas diversas maneiras como elas são vividas pelos jogos de inter-relações entre sociedades e jovens. Por exemplo, as experiências múltiplas nas famílias, escolas, religiosidades, movimentos sociais, grupos sociais, de informação, arte, lazer e entretenimento, possibilitam enxergar não apenas uma juventude e sim juventudes, inseridas e que se inserem em diversos contextos socioculturais.

Para se ter uma ideia desses jogos socioculturais, observamos que, nas infâncias, geralmente se tem uma perspectiva da família como seu primeiro convívio social, onde aprendem valores, normas e condutas. Assim sendo, esses jovens referenciados primeiramente 
por seus núcleos familiares nas infâncias, desdobram para o local em que eles são inseridos, como na escola, em lazeres, rodas de amigos, obtendo informações externas (fora do núcleo familiar), formando novas perspectivas, onde se veem diante de "novos" valores, "novos" elementos culturais, e constroem outros olhares com características multifacetadas.

Quando se busca remeter à análise das condições juvenis, está se propondo fazer isso pelas práticas sociais sob a perspectiva de mudanças sociais, o que exige uma atenção para as disposições coletivas e as escolhas por projetos individuais e o campo de possibilidades onde se situam os agentes. Deste modo, ainda que referida a um indivíduo, uma prática individual sempre estará relacionada com a prática social da coletividade à qual o indivíduo está ligado. Essa forma de pensar tem a ver com o que Norbert Elias definiu como a interdependência entre o indivíduo e o coletivo.

Essas interdependências salientadas por Elias apontam para a estruturação do conceito de figuração social, que pode ser entendida como as inter-relações entre indivíduo e sociedade. É importante salientar que tanto a sociedade quanto os indivíduos podem ser influenciados nas figurações. Segundo o autor, as figurações são redes de interdependência humanas moldadas por formas estruturais específicas, porém flexíveis e sujeitas a constantes transformações. Podemos considerar, portanto, as condições juvenis como figurações sociais específicas. Nelas, redes de interdependência são constituídas pelos jovens que se ligam, voluntária e involuntariamente, por meio de suas inclinações e necessidades às suas famílias, trabalhos, escolas, religiosidades, lazer, sexualidades, tecnologias digitais, drogas, entre outras.

É relevante compreender como essas figurações sociais específicas se inter-relacionam $\mathrm{com} /$ pelos jovens de forma a criar redes de interdependência estável ou não. Mais do que isso, o interagir ou desvincular-se de outras figurações sociais, por exemplo, deixar de frequentar a escola, pode estar associado à outros elementos como, por exemplo, a gravidez precoce, necessidade de trabalhar para auxiliar os familiares, envolvimento com drogas, entre outros. Essas teias de interações serão analisadas no decorrer deste trabalho como teias sociais.

Nesse sentido, o trabalho tem como proposta entender como esses jovens se constroem dentro e fora do ambiente escolar, já que conhecer a vida deles ultrapassa o espaço escolar. $\mathrm{Na}$ verdade, a escola passa a ser o ponto de referência que possibilita enxergar as trajetórias de seus modos de vida nas várias teias que são construídas de forma contínua ou descontínua.

\section{CONDIÇÕES JUVENIS: JUVENTUdES E SUAS TEIAS DE INTERAÇÕES}

Por diversas vezes, a juventude é encarada como uma fase da vida na qual seus atores são vistos como imaturos e inconsequentes, ou seja, sem preparação para assumirem certas responsabilidades. Contudo, outrora ela era mensurada por sinais de compromisso para com a moral e os valores da época, sendo suprimida pelos arroubos de um casamento arranjado. Assim, entende-se que as concepções que norteiam o papel social do jovem vêm se alterando ao longo do tempo, sendo ditadas por interesses e entendimentos que não o consideram em sua completude, desconsiderando a heterogeneidade dos seus modos de ser. Para Carrano \& Dayrell (2013): 
[...] a juventude aparece como uma categoria socialmente destacada nas sociedades industriais modernas, resultado de novas condições sociais como as transformações na família, a generalização do trabalho assalariado e o surgimento de novas instituições, como a escola. Nesse processo, começou-se a delinear a juventude como uma condição social definida além dos critérios de idade e/ ou biológicos (p. 15).

Essa guinada no processo social do lugar da juventude aponta, como lembra Dayrell (2003, p. 40), "para a necessidade de compreendê-los como sujeitos sociais, que constroem um determinado modo de ser jovem, baseados em seu cotidiano". Porém, torna-se perceptível que a escola como um instrumento de manutenção do Estado passa a desempenhar uma função socializadora, assumindo, em muitos casos, a frente do processo de homogeneização desses sujeitos. Desconsiderando que seus frequentadores possuem perspectivas e maneiras distintas de se relacionar com o mundo, visto às singularidades de cada contexto social. Nesse sentido, segundo Dayrell (2003):

Nos deparamos no cotidiano com uma série de imagens a respeito da juventude
que interferem na nossa maneira de compreender os jovens. Uma das mais ar-
raigadas é a juventude vista na sua condição de transitoriedade, na qual o jovem
é um "vir a ser", tendo no futuro, na passagem para a vida adulta, o sentido das
suas ações no presente (p. 40).

Sob essa perspectiva, Brandão (1983) salienta que a escola e os seus profissionais tendem a não levar em conta as expectativas, demandas e necessidades de alunos que advêm de espaços socioculturais com práticas e costumes que destoem da cultura aceita socialmente e disseminada nesses espaços de educação formal, desencadeando, por exemplo, processos como o de exclusão escolar. Entretanto, Peregrino \& Carrano (2004) apontam que conhecer a realidade dos atores que compõem essa esfera torna-se um fator preponderante para o processo de significação proximal destes para com a instituição. Pois, como afirma Carrano (2002), o fundamental para a juventude não é simplesmente a construção de metas para o seu futuro, mas viver o presente por meio das experiências que podem produzir.

Portanto, o jovem pode ser entendido como aquele que significa seus espaços por meio de suas vivências, considerando as diversas experiências pelas quais passa ao longo de sua vida como reflexo direto ou indireto de suas ações. Nesse sentido, Melucci (1992) destaca que o entendimento desse sujeito está relacionado com a compreensão dos seus modos de construção identitárias que, por sua vez, permitem a compreensão de suas ações.

Tal discussão evidencia a condição do jovem como ser autônomo e dotado de reflexividade, ultrapassando os preceitos que o consideram, como aponta Pais (1993), ao trazer para a contenda reflexões acerca de Bourdieu, a juventude como uma categoria manipulável socialmente. Desta maneira, concorda-se com Elias (1994b, p. 249), ao afirmar que: 
luto ou total) de autonomia face a de outras pessoas e que, na realidade, durante toda a vida é orientada para outras pessoas e dependente delas. A rede de interdependências entre os seres humanos é o que os liga. Elas formam o nexo do que aqui é chamado configuração, ou seja, uma estrutura de pessoas mutuamente orientadas e dependentes. Uma vez que as pessoas são mais ou menos dependentes entre si, inicialmente por ação da natureza e mais tarde através da aprendizagem social, da educação, socialização e necessidades recíprocas socialmente geradas, elas existem, poderíamos nos arriscar a dizer, apenas como pluralidades, apenas como configurações.

Tal colocação provoca reflexões acerca do procedimento de comparação sistemática entre as estruturas interdependentes em seu desenvolvimento temporal utilizado por Norbert Elias, o qual utilizou o conceito de estrutura conservando a dinâmica processual característica de uma dada sociedade. Diante dessa perspectiva, aponta-se para o caráter teórico desse entendimento no que concerne à busca pela compreensão dos modos de ser jovem e suas implicações para a construção e reconstrução dos seus espaços socializadores.

Ao compreender a sociedade como processual, Elias (1994b) dá elementos para pensar os jovens e suas diversas formas de representação instituídas ao longo dos tempos. Assim como Pais (1993), acredita-se que a juventude pode ser considerada como uma construção sociológica que sofrerá modificações conforme a sociedade o sofre.

Nesse sentido, Melucci (1992, p. 14) ressalta que a mudança no comportamento dos jovens tem forte relação com o tipo de sociedade, pois:

As diferenças ente os tempos internos e os tempos sociais não são uma novidade das culturas. Mas nas sociedades do passado, a relativa homogeneidade e a lentidão das mudanças garantiam uma certa integração entre a experiência temporal subjetividade vivida e as definições do tempo reguladas socialmente.

Além do mais, Elias (1994a) argumenta que cada homem singular apresenta um caráter específico que partilha com outros membros da sociedade, o qual the daria a identidade que o distingue dos demais membros da coletividade, mas que permite uma integração social. Segundo esse autor:

Cada pessoa singular, por mais diferente que seja de todas as demais, tem uma composição específica que compartilha com outros membros e sua sociedade. Esse habitus, a composição social dos indivíduos, como que constitui o solo de que brotam as características pessoais mediante as quais um indivíduo difere dos outros membros de sua sociedade. Dessa maneira, alguma coisa brota da linguagem comum que o indivíduo compartilha com outros e que é, certamente, um componente do habitus social - um estilo mais ou menos individual algo que poderia ser chamado de grafia individual inconfundível que brota da escrita social (ELIAS, 1994a, p. 150).

Acredita-se que o habitus pode representar linhas de intersecção entre o indivíduo e a sociedade, que podem ser expressas pelas relações de interdependência enviesadas por ações 
individuais que refletem as diferentes configurações com as quais os mesmos estão envolvidos, podendo ser geradas pelos processos de continuidade e descontinuidade que se desdobram mediante suas vivências. Portanto, tem-se que as figurações sociais e os modos como se apresentam para o indivíduo podem influenciar diretamente na construção de seus habitus.

No entanto, o habitus nas diversas condições juvenis adjetiva concepções díspares, muitas vezes os jovens com o anseio de conseguir a liberdade que desejam recorrem a meios para "apressar" a chegada da vida adulta. Nesse momento, é de grande relevância a interação de figurações sociais para além da família, como os amigos, escola, entre outros que possam estar reconstruindo vínculos da própria dinâmica moderna. Para Carrano \& Dayrell (2013):

Uma das mais importantes tarefas das instituições educativas hoje está em contribuir para que os jovens possam realizar escolhas conscientes sobre suas trajetórias pessoais e constituir os seus próprios acervos de valores e conhecimentos não mais impostos como heranças familiares ou institucionais. $O$ peso da tradição encontra-se diluído e os caminhos a seguir são mais incertos (p. 20).

Outro aspecto importante do habitus de grupos juvenis é a necessidade de se sentir aceito pelo grupo onde deseja participar, procurando sempre os grupos com os quais mais se identificam, participando dos grupos sociais os jovens também constroem suas identidades. "O indivíduo enquanto ser social, forma sua identidade através do processo de socialização" (BERGER; BERGER, 1978). Daí a importância de se conhecer os jovens em seus processos de interação social, objetivo central deste trabalho.

\section{ESCOLARIZAÇÃO, JUVENTUDES E FIGURAÇÕES SOCIAIS}

Os jovens experimentam a juventude mediante a ressignificação de normas e valores que se desdobram em seus diferentes espaços de sociabilidade, sejam eles físicos ou simbólicos. Nesse sentido, acredita-se que os processos de construção identitária são permeados pelas suas subjetividades, que são atravessadas pelas suas vidas cotidianas. Portanto, concordando com Elias (1994a), o presente tópico propõe uma análise acerca das figurações de jovens do ensino médio da cidade de Parnaíba-PI, por meio de dados que versam suas experiências socioculturais.

Para o entendimento acerca dos aspectos conceituais que envolvem o pressuposto citado, destaca-se que, segundo Wautier (2003, p. 188) em François Dubet, "a experiência social é a atividade, o trabalho pelo qual o indivíduo pode construir uma identidade social, quando articula as diversas lógicas de ação nas quais ele está engajado". Sendo um sujeito dotado de reflexividade, que sofre as influências do seu meio e age sobre ele. Na verdade, para Elias (1994a):

Cada pessoa nesse turbilhão faz parte de um determinado lugar [...] A ordem invisível dessa forma de vida em comum, que não pode ser diretamente percebida, oferece ao indivíduo uma gama mais ou menos restrita de funções e 
modos de comportamento possíveis [...] Numa palavra, cada pessoa que passa por outra, como estranhos aparentemente desvinculados na rua, está ligada a outras por laços invisíveis, sejam estes laços de trabalho e propriedade, sejam de instintos e afetos (p. 21-22).

Essa teia de conexão, visível e invisível, pode ser visualizada pelos jovens que se submetem a ela, evidenciando assim a heterogeneidade pela qual os modos de ser e viver da juventude têm se apresentado, Groppo (2000, p. 15) a considera como uma:

Representação e uma situação social simbolizada e vivida com muita diversidade na realidade cotidiana, devido à sua combinação com outras situações sociais - como a de classe ou estrato social -, e devido também as diferenças culturais, nacionais e de localidade, bem como ás distinções de etnia e de gênero.

Tomando como base tal caracterização, é válido colocar que os diferentes atores juvenis devem ser encarados em sua totalidade, considerando as diferentes perspectivas que caracterizam os seus espaços de socialização como uma dimensão dessa categoria. Abramo (2005, p. 43) pondera acerca de sua multiplicidade, ao apontar não só a escola e a família como instâncias socializadoras, referendando a "importância dos campos de lazer e da cultura, principalmente na constituição da sociabilidade, das identidades e da formação de valores".

As nuanças que engendram a situação juvenil na atualidade, não permitem, como salienta Pais (2001), concebê-la como uma fase da vida em sua singularidade, mas em sua diversidade, não se restringindo a uma juventude, mas a "juventudes" que compartilham diferentes maneiras de se relacionar com a família, com a escola, com a rua e até mesmo com os que dividem a mesma faixa de idade. Nesse sentido, observa-se que:

A existência da pessoa como ser individual é indissociável de sua existência como ser social. [...] Não há identidade-eu sem identidade-nós. Tudo o que varia é a ponderação dos termos na balança eu-nós, o padrão da relação eu-nós (ELIAS, 1994a, p. 151-152).

Por meio do exposto, e a fim de trazer mais clareza para as discussões subsequentes, destaca-se que os diálogos entre as estatísticas e as teorias vislumbradas por esta e outras pesquisas pautadas na temática em questão veem a escola como um espaço permeado pela conjuntura social, cultural e econômica. Considerando, como Nosella (2005, p. 227), que "a escola não se explica por ela própria e sim pela relação política que ela mantém com a sociedade".

Os entendimentos que versam sobre os fatores internos e externos à escola são subsidiados pelos modos como seus atores se constroem no ir e vir de suas escolarizações e cotidianidades, dentro e fora do ambiente escolar. Cara, Silva e Papa (2006, p. 20), ao trazer para a frente da discussão segmentos desses atores, evidenciam que: 
A vivência juvenil na contemporaneidade tem se mostrado mais complexa, combinando processos formativos com processos de experimentação e construção de trajetórias que incluem a inserção no mundo do trabalho, a definição de identidades, a vivência da sexualidade, da sociabilidade, do lazer, da fruição e criação cultural e da participação social.

Diante disso, sugere-se que tal complexidade, aliada às reformas educacionais instituídas ao longo do processo de democratização do ensino, podem ser diretamente proporcionais ao aumento do número de jovens que procuram manter-se na escola, ao passo que desempenham outras funções na esfera social. Podendo, por exemplo ser trabalhador e estudante - apenas estudante - estudante, chefe de família e trabalhador - etc. Essas esferas de conexão experienciadas pelos jovens remetem à noção de figurações elucidada por Elias $\&$ Scotson (2000), principalmente porque:

Dizer que os indivíduos existem em configurações significa que o ponto de partida de toda investigação sociológica é uma pluralidade de indivíduos, os quais, de um modo ou de outro, são interdependentes. Dizer que as configurações são irredutíveis significa que nem se pode explicá-las em termos que impliquem que elas têm algum tipo de existência independente dos indivíduos, nem em termos que impliquem que os indivíduos, de algum modo, existem independentemente delas (p. 184).

Desse modo, tais figurações trazem para o âmbito educacional novas modalidades que buscam o atendimento de uma demanda cada vez mais distinta. É o que afirmam Souza e Oliveira (2008, p. 9) quando dizem que:

As ampliações da demanda associadas às modificações em curso no processo produtivo têm trazido à escola média desde recém-egressos do Ensino fundamental até trabalhadores que retornaram a ela após período de afastamento, em busca de qualificação ou simplesmente de certificação de estudos, crescentemente exigidos no mercado de trabalho, além da tradicional busca de acesso ao nível superior.

Essa dinamização dos sujeitos vem trazendo desafios gerais e particulares para as instituições de nível médio, pois, suas variações se encontram regidas pela mesma Lei de diretrizes e bases da educação nacional de 1996, não possuindo uma identidade própria. Logo, mediante as demandas dos sujeitos, aponta-se que ele pode ser caracterizado como propedêutico ou profissionalizante, podendo ser ofertado em diferentes turnos.

Segundo Abramovay e Castro (2003, p. 153), a referida lei, que foi

Promulgada em 1996, determina que o ensino médio deve fazer parte da educação básica. A partir de então, tornou-se um compromisso do Estado garantir a oferta desse nível de ensino, com o objetivo de proporcionar aos cidadãos brasileiros um maior aprofundamento de seus estudos e dotá-los de maior capacidade de intervenção no mercado de trabalho e do capital cultural necessário ao 
exercício da cidadania, assim como condições, no plano do conhecimento, para prosseguir a trajetória de estudos em níveis superiores. Ao designar o ensino médio como a última etapa do ciclo de educação básica, a nova LDB estabelece para a escola média a terminalidade de um processo educativo com funções específicas, com vistas a propiciar aos alunos as competências necessárias para que eles possam continuar aprendendo.

Teoricamente, a oferta dessa modalidade de ensino em diferentes turnos viria corroborar com o processo de democratização da educação, ao passo que garante as mais variadas instâncias da sociedade gozar da mesma oportunidade de acesso a níveis cada vez mais altos de escolaridade. Portanto, como afirma Dayrell (2013, p. 81), as escolas passaram a "receber um contingente de alunos cada vez mais heterogêneo, marcado pelo contexto de uma sociedade desigual, com altos índices de pobreza e violência que delimitam os horizontes possíveis de ação dos jovens na sua relação com essa instituição".

Sendo esse relacionamento influenciado por diversos aspectos da vida cotidiana, o jovem começa a ponderar suas escolhas. Isso posto, a depender de suas possibilidades ele "opta" pela instituição que melhor dialoga com seus anseios no tempo presente e perspectivas para o futuro. Contudo, e diante das duras realidades nas quais estão inseridos os estudantes e as escolas públicas brasileiras, os ditames da lei não funcionam como deveriam, havendo fortes variações nos contextos e turnos nos quais se desdobram os processos de ensino e aprendizagem.

Referendando o anunciado restritivo das ações dos sujeitos, estudiosos como Abramovay e Castro (2003), em seu relatório de pesquisa acerca do ensino médio e as suas múltiplas vozes, assim como Sousa e Oliveira (2008), em seus estudos acerca da democratização e diversidade do ensino médio noturno, consideram os horários de funcionamento das escolas como preponderantes na qualidade do ensino.

Em suas pesquisas, destacam que os alunos que frequentam o ensino médio no turno da noite tendem a ser lesados por problemas que giram em torno da estrutura, das condições de trabalho ofertado aos profissionais e por seus próprios enfrentamentos individuais, tendo em vista que estes, em muitos casos, vêm de sua terceira jornada diária, não podendo migrar para o diurno. Geralmente, tal processo migratório é inviabilizado pela ausência de vagas no turno da manhã e da tarde, ou pelos diversos condicionamentos que engendram a vida dos que o compõem.

Desse modo, é válido ressaltar que as regras ocultas no tabuleiro chamado escola vão gerando entre os turnos diferentes jovens com discrepâncias que podem ser caracterizadas pelo perfil dos sujeitos que o frequentam. Sendo a idade, o estado civil, a relação com a família e o mundo do trabalho indispensáveis para o entendimento das teias de conexão entre os diversos sujeitos e essas figurações sociais, que podem e devem estar dentro e/ou conectadas em outras figurações. 


\section{Processo metodológico}

Este estudo ${ }^{1}$ foi realizado sob uma abordagem quantitativa que, de acordo com Richardson (1989, p. 70), "caracteriza-se pelo emprego da quantificação, tanto nas modalidades de coleta de informações, quanto no tratamento dessas através de técnicas estatísticas, desde as mais simples até as mais complexas".

As técnicas utilizadas foram a análise das fichas informativas com dados sobre o ensino médio de Parnaíba e também o questionário, com questões de respostas objetivas, com a finalidade de caracterizar as teias de interação desses jovens, possibilitando que um maior número de estudantes falasse de suas juventudes e suas relações com outras figurações sociais.

Para a aplicação dos questionários, utilizou-se uma amostra do tipo intencional, onde o critério para participar desse momento foi ser aluno regular do Ensino Médio em qualquer turno, de duas das escolas dessa cidade, especificamente a que apresentar, de um lado, o maior índice de evasão/reprovação e, de outro lado, maior aprovação/conclusão do ensino médio, no ano de 2014. Salienta ainda que os respondentes da pesquisa estavam cursando o primeiro e terceiro anos do ensino médio, contudo, em duas escolas que, além de contraporem no quesito aprovação/evasão, uma é regular em regime de funcionamento integral (E.A) e outra noturna (E.B). É importante dizer também que o número selecionado foi feito de acordo com a disponibilidade dos jovens em responder aos questionários.

As principais variáveis empregadas foram: Idade, Sexo, Estado civil, Formação do pai, Formação da mãe, Incentivo a frequentar a escola, Incentivo dos pais para frequentar a escola, Onde estão os melhores amigos, Sentem-se bem na escola, Deseja mudar de escola, Gosto da maioria dos meus professores, Posso contar com meus professores, Posso contar com a equipe técnica da escola, Parou de estudar para trabalhar, Situação de trabalho, Renda, A família recebe auxílio/bolsa e Práticas de lazer.

Após a coleta, os dados coletados foram digitados e analisados em planilha do software Statistical Packege for Social Sciences (SPSS) pela equipe que obteve as informações. Vale ressaltar a importância dessa etapa pois pôde-se diminuir em parte a possibilidade de ocorrência de erros, visto que os digitadores tiveram familiaridade com os dados que foram processados. Por sua vez, a adoção de uma tabulação e codificação das informações preservando uma numeração simples foi usada para facilitar a digitação. Também foi utilizado para a análise das informações uma estatística descritiva simples.

\section{Figurações de jovens em duas escolas do ensino médio de Parnaíba-PI}

Para se ter uma ideia das características presentes nas figurações de jovens, passaremos a apresentar o caso desses sujeitos em duas escolas do Ensino Médio de Parnaíba-PI. Uma

Foi submetido ao Comitê de Ética em Pesquisa da Universidade Federal do Piauí, após o parecer favorável, sob número 53202915.1.0000.5669, foram contatadas as instituições para o acesso aos sujeitos da pesquisa. 
primeira figuração a ser observada é a que se denominou de juventudes escolares do Ensino Médio. Podemos remeter a ligação dessa categoria, por um lado, à faixa etária, especificamente porque as políticas de Estado no Brasil têm compreendido como jovens aqueles que apresentam idades entre 15 e 29 anos. Não obstante, Brenner e Carrano (2014, p. 1.225) apontem três grupamentos dentro desse mesmo intervalo. Segundo os estudiosos, tomando como base a "PEC da juventude" que passou a vigorar no ano de 2010, são considerados jovens-adolescentes aqueles com idades entre 15 e 17 anos, jovens-jovens os que se apresentam entre os 18 e 24 anos e jovens adultos aqueles que estão entre os 25 e os 29 anos.

Ao serem consideradas essas faixas de idade, os pesquisadores supracitados contam que "o público esperado para o ensino médio regular é aquele composto por jovens compreendidos entre 15 e 17 anos". No entanto, ao considerar a distorção idade-série, tem-se que o público que faz o ensino médio noturno está, na maioria dos casos, entre as categorias jovens-jovens e os jovens-adultos.

Para um melhor entendimento dessa relação entre indivíduo e sociedade, é fundamental que as especificidades apresentadas por ambas as faixas de idades sejam consideradas. Para tanto, o presente estudo vem por meio destas colocações e análise dos dados subsequentes pensar as figurações manifestas ao longo deste escrito, vislumbrando os modos como elas constroem e são construídas pelos jovens estudantes.

Com base nos dados da Tabela 1, é possível ratificar a pesquisa de Brenner e Carrano (2014), principalmente no que se refere às categorias jovens-adolescentes e jovens-jovens. Verificou-se que a maioria dos respondentes deste estudo que frequentam o ensino noturno (E.B) são jovens-jovens e os do regular (E.A), jovens-adolescentes. Logo, os modos de ser e estar desses na sociedade são influenciados pelos aspectos que giram em torno de suas relações com o meio, constituídas por características de sua vida particular, que apresentam possibilidades ou imposições para a vivência de suas condições juvenis.

Tabela 1: O perfil dos sujeitos entrevistados

\begin{tabular}{|l|c|c|c|l|}
\hline Características & N (E.A) & $\%$ & N (E.B) & $\%$ \\
\hline Média de Idade (anos) & 12 & 80,0 & 1 & 06,7 \\
$15-17$ & 03 & 20,0 & 14 & 93,3 \\
$18-21$ & & & & \\
\hline Sexo & 07 & 46,7 & 06 & 40,0 \\
Masculino & 08 & 53,3 & 09 & 60,0 \\
Feminino & 15 & 100 & 12 & 80,0 \\
& 0 & 0 & 03 & 20,0 \\
\hline Estado civil & & & & \\
Solteiro (a) & & & & \\
Casado (a)/ mora junto & & & & \\
& & & & \\
\hline
\end{tabular}

Fonte: Pesquisa de campo, 2016. 
As figurações educacionais nas quais esses jovens estão inseridos possuem características coletivas de certa faixa etária. Isso se dá porque permanecem interagindo nessa teia os sujeitos que podem ser relacionados dentro da longevidade de suas trajetórias educacionais com expectativas delineadas em outras figurações. Na verdade, ao depender dos elementos desencadeados na vida familiar, trabalho, amigos e lazer, por exemplo, os jovens tendem a abandonar a escola para atenderem às demandas que se colocam mais emergentes momentaneamente, desvinculando-se daquela interação (escola) que se mantém com regras que reproduzem prazos para permanecer no espaço, conforme observado em outro estudo realizado em uma dessas escolas, com maior número de evasão escolar (MELO; SANTANA, 2017).

Por sua vez, vale salientar que a depender da forma como são figuradas essas teias que se desvinculam da educação formal, há elementos nelas que as conectam. A saber, a formação dos pais, recebimento pela família de auxílio para manter o filho na escola, o incentivo familiar de sua importância para ascensão social, amizades firmadas, lazer pelo conhecimento proporcionado na escola e reconhecimento de que o ganho com o trabalho do momento pode aumentar com título acadêmico.

Quando remetido às teias da figuração Família, que podem ou não conectar esses jovens à escola, observou que na E.A a maioria (66,7\% Pai - 93,3\% Mãe) dos pais tem ensino básico incompleto ou completo. E muitos $(60 \%)$ deles incentivam os filhos a frequentarem a escola. Situação próxima pode ser vista na E.B, conforme Tabela 2. O que traz uma diversidade, de alguma forma, dos argumentos levantados por Carrano \& Dayrell (2013), para os quais

[...] a escola pode ser muito diferente para jovens de classe média, filhos de pais escolarizados. Para eles, uma longa escolarização é algo esperado e na qual "apostam suas fichas". Para jovens das camadas populares, as experiências dos pais e de outros amigos de bairro nem sempre acenam para um futuro promissor a partir da escolarização (p. 50).

Carrano \& Dayrell (2013) salientam ainda outras figurações que se conectam (ou não) para a escolarização juvenil. No caso deste estudo, pode ser vislumbrado pela Tabela 2 a experiência da maioria $(66,7 \%)$ dos jovens da E.A em vincular-se com os amigos estudantes desse espaço poder ser um incentivador para permanecerem na escola, já que existem outros incentivadores a essa manutenção que não são os pais. No entanto, não queremos apontar esse argumento como fator determinante, pois na E.B uma grande proporção $(73,3 \%)$ dos amigos deles está fora da escola, mas há uma motivação em permanecer estudando. Há de se destacar ainda que:

\footnotetext{
Nas interações com os amigos, os jovens "trocam ideias", produzem valores, hierarquizam relações e recriam os tempos e espaços escolares. Nessas interações, os jovens elegem os "amigos do peito", circulam entre turmas e "galeras", sem um tempo predefinido, no lazer ou no uso do tempo livre (CARRANO \& DAYRELL, 2013, p. 51).
} 
Aliás, essa dimensão do lazer argumentada por esses autores pode manter-se como um prolongamento das teias salientadas, o que possibilita conectar-se com a escola. Para os jovens da E.A, quando não estão trabalhando ou estudando, a maioria $(73,3 \%)$ gosta de passear, assistir TV, ir ao cinema e fazer atividades esportivas. Essas práticas, quando realizadas em grupos, são praticadas com familiares e/ou amigos da escola, pois muitos dos seus amigos estão na escola. No caso da E.B, a maioria (73,3\%) prefere ficar em casa, assistindo TV, lendo e na internet, sozinhos ou com a família. Embora não seja com amigos da escola, não se pode descartar que esses elementos e familiares não sejam propagadores para a manutenção desses jovens no espaço escolar.

$\mathrm{Na}$ verdade, essas dimensões de inter-relação desses jovens possibilitam pensar, como aponta Dayrell (2005, p. 1-2), que:

É nesse processo, permeado de descobertas, emoções, ambivalências e conflitos, que o jovem se defronta com perguntas como: "quem sou eu?", "para onde vou?", "qual rumo devo dar à minha vida?". Questões cruciais que remetem à identidade e ao projeto de vida, duas dimensões que aparecem interligadas e são decisivas no processo de amadurecimento. O projeto de vida pode ser entendido como a ação do indivíduo de escolher um, dentre os futuros possíveis, transformando os desejos e as fantasias que lhe dão substância em objetivos passíveis de serem perseguidos, representando, assim, uma orientação, um rumo de vida. Os projetos podem ser individuais e/ou coletivos; podem ser mais amplos ou restritos, com elaborações a curto ou médio prazo, dependendo do campo de possibilidades. Quer dizer, dependem do contexto sócio- econômico- cultural concreto no qual cada jovem se encontra inserido, e que circunscreve suas possibilidades de experiências. O projeto possui uma dinâmica própria, transformando-se na medida do amadurecimento dos próprios jovens e/ou mudanças no campo de possibilidades.

Diante dessa argumentação, o autor deixa margem para serem discutidos os jogos socioculturais nos quais esses jovens se inserem. Entre eles, chama a atenção o contexto econômico como um forte protagonista desse processo (mas que pode ser corrompedor na teia de interação com a escola), pois tende a contribuir diretamente para as relações estabelecidas nas diversas instâncias da vida dos mesmos. Para se ter uma ideia, conforme a Tabela 2, com relação aos jovens entrevistados, observou na E.B, quando questionados sobre suas relações com o mundo do trabalho, que $26,7 \%$ afirmaram nunca terem exercido uma atividade profissional, enquanto que outros $53,3 \%$ já trabalharam, mas estão desempregados atualmente, sendo que apenas $13,3 \%$ estão inseridos no mercado de trabalho e $6,7 \%$ à procura de um emprego. Na E.A, o número de jovens que nunca trabalharam é superior, chegando a $60 \%$ do total, enquanto que apenas 33,3 já exerceram uma atividade remunerada e outros $6,7 \%$ afirmaram estar procurando um trabalho. Isso acontece pelo fato de que:

Não podemos esquecer que grande parte dos jovens que frequentam o ensino médio em nossas escolas públicas aliam, ao lado da sua condição de jovens, a situação de pobreza. Esta dupla condição social e econômica interfere dire- 
tamente na trajetória de vida e nas possibilidades e sentidos que assumem a vivência juvenil. Para estes jovens, um grande desafio cotidiano é a garantia da própria sobrevivência, numa tensão constante entre a busca de gratificação imediata e um possível projeto de vida (CARRANO \& DAYRELL, 2013, p. 35).

Infere-se ainda que a maioria $(73,3 \%)$ dos jovens da E.B tem uma renda familiar de até três salários, o que traz certa relação com o status de trabalho salientado na Tabela 2. Já a maior parte $(80 \%)$ dos estudantes da E.A não tem dimensão da renda da família. Por sua vez, há de se considerar que em um pouco mais da metade $(53,3 \%$ E.A e $60,0 \%$ E.B) deles, as famílias recebem algum tipo de bolsa para permanecerem na escola, do tipo bolsa família etc., ajudando-os na permanência na escola. Esses elementos dão subsídios para pensar que quanto menor for o capital econômico, tanto maior são as inclinações para o mercado de trabalho e distanciamento para com a escola, pois estes ficam impossibilitados de viverem suas condições juvenis para auxiliarem com o sustento da família. Nas palavras de Sposito (2005, p. 106):

Para os jovens brasileiros, escola e trabalho são projetos que se sobrepõem ou poderão sofrer ênfases diversas de acordo com o momento do ciclo de vida e as condições sociais que lhes permitam viver a condição juvenil. Por essas razões, a experimentação e a reversibilidade de escolhas aparecem como fatores importantes para compreender as relações dos jovens tanto com a escola como com o mundo do trabalho, situando-as na dimensão do tempo como uma construção social e cultural em que articulam demandas do presente e projetos para o futuro.

Com base nesses dados, percebe-se que uma parcela significativa dos jovens já vivenciou uma experiência trabalhista enquanto eles estudavam. Contudo, ressalta que os trabalhos desenvolvidos por essa maioria não eram de caráter formal, e suas implicações na vida desses jovens correspondiam à vivência de suas condições juvenis, podendo isso ser negociado com a frequência à escola. Atualmente, a maioria dos estudantes deste estudo está desempregada, e isso desperta questões que versam a sua permanência no âmbito escolar, ao conseguirem um trabalho formal e/ou assumirem responsabilidades maiores.

Situar a relação entre trabalho formal e evasão escolar é uma questão central a ser posta, principalmente porque os maiores índices de evasão estão concentrados no primeiro ano do nível de ensino em questão, sendo motivados pela entrada no mercado de trabalho, gravidez, casamento, baixo rendimento escolar entre outros fatores. O que, para Abramovay \& Castro (2003, p. 535), pode estar relacionado com

\footnotetext{
As necessidades de sobrevivência e maiores problemas de conciliação entre estudo e experiências de vida extra-escola, assim como à inadequação das escolas em lidar com alunos com tais demandas. Não se descarta também a relação entre abandono, frustrações e desencantos com a escola.
}

Nesse sentido, Dayrell (2010, p. 87) afirma que "se para muitos jovens é possível a conciliação entre o trabalho e a escola, para outros essa coexistência não se dá sem conflitos 
que são decisivos para a evasão da escola". No entanto, as interações entre os indivíduos internos à escola não parece um elemento gerador, pelo menos para a maioria dos entrevistados, de frustrações e desencantos com a escola. Isso pode ser confirmado com esses estudantes que firmam um laço de estabilidade com suas escolas. Para se ter uma ideia, todos os jovens da E.A sentem-se bem quando estão nela, o que se verifica também na maioria $(93,3 \%)$ da E.B. Vale associar que muitos (66,7\% E.A e 93,3\% E.B) desses jovens pretendem continuar estudando nessas escolas.

É válido destacar ainda que as aproximações desses jovens no espaço escolar não se dão somente pelos amigos da escola e de outras figurações, fazem parte dos elementos internos de interação a maneira como eles enxergam/interagem com seus professores e coordenadores pedagógicos. Pode-se dizer que a maioria $(86,7 \%)$ dos estudantes da E.A gosta de grande parte dos seus professores e eles sentem (73,3\%) que podem contar com eles. Uma aproximação maior $(93,3 \%)$ é vista com seus coordenadores pedagógicos. Com rumo parecido, elenca-se a E.B, conforme Tabela 2.

É importante dizer que embora haja essa interação com muitos professores e coordenadores, os estudantes podem se afastar dessa figuração, devido principalmente à forma como os outros (professores e coordenadores) se posicionam a partir de uma relação de poder, gerando assim uma fragmentação dentro das teias de interação atuais, como também da relação do jovem com seus projetos de futuro e muitos outros.

Tabela 2: Elementos que (des)vinculam jovens à educação formal

\begin{tabular}{|c|c|c|c|c|}
\hline Características & $\mathrm{N}$ (E.A) & $\%$ & $\mathrm{~N}$ (E.B) & $\%$ \\
\hline $\begin{array}{l}\text { Formação do pai } \\
\text { Sem escolarização } \\
\text { Ensino básico (in)completo } \\
\text { Ensino Superior/Pós-graduação (in)completo }\end{array}$ & $\begin{array}{l}03 \\
10 \\
02\end{array}$ & $\begin{array}{l}20,0 \\
66,7 \\
13,3\end{array}$ & $\begin{array}{l}05 \\
09 \\
01\end{array}$ & $\begin{array}{c}33,3 \\
60,0 \\
6,7\end{array}$ \\
\hline $\begin{array}{l}\text { Formação da mãe } \\
\text { Sem escolarização } \\
\text { Ensino básico (in)completo } \\
\text { Ensino Superior/Pós-graduação (in)completo }\end{array}$ & $\begin{array}{c}0 \\
14 \\
01\end{array}$ & $\begin{array}{c}0 \\
93,3 \\
6,7\end{array}$ & $\begin{array}{c}04 \\
11 \\
0\end{array}$ & $\begin{array}{c}26,7 \\
73,3 \\
0\end{array}$ \\
\hline $\begin{array}{l}\text { Incentivo a frequentar a escola } \\
\text { Sim } \\
\text { Não }\end{array}$ & $\begin{array}{c}15 \\
0 \\
\end{array}$ & $\begin{array}{c}100 \\
0\end{array}$ & $\begin{array}{l}10 \\
05 \\
\end{array}$ & \begin{tabular}{|l}
66,7 \\
33,3 \\
\end{tabular} \\
\hline $\begin{array}{l}\text { Incentivo dos pais para frequentar a escola } \\
\text { Sim } \\
\text { Não }\end{array}$ & $\begin{array}{l}09 \\
06\end{array}$ & $\begin{array}{l}60,0 \\
40,0\end{array}$ & $\begin{array}{c}10 \\
0\end{array}$ & $\begin{array}{c}100 \\
0\end{array}$ \\
\hline $\begin{array}{l}\text { Onde estão os melhores amigos } \\
\text { Escola } \\
\text { Fora dela }\end{array}$ & $\begin{array}{l}10 \\
05\end{array}$ & $\begin{array}{l}66,7 \\
33,3\end{array}$ & $\begin{array}{l}04 \\
12\end{array}$ & $\begin{array}{l}26,7 \\
73,3\end{array}$ \\
\hline
\end{tabular}




\begin{tabular}{|c|c|c|c|c|}
\hline Características & $\mathrm{N}$ (E.A) & $\%$ & $\mathrm{~N}(\mathrm{E} . \mathrm{B})$ & $\%$ \\
\hline $\begin{array}{l}\text { Sentem-se bem na escola } \\
\text { Sim } \\
\text { Não }\end{array}$ & $\begin{array}{c}15 \\
0 \\
\end{array}$ & $\begin{array}{c}100 \\
0 \\
\end{array}$ & $\begin{array}{l}14 \\
01 \\
\end{array}$ & $\begin{array}{c}93,3 \\
6,7 \\
\end{array}$ \\
\hline $\begin{array}{l}\text { Deseja mudar de escola } \\
\text { Sim } \\
\text { Não }\end{array}$ & $\begin{array}{l}05 \\
10 \\
\end{array}$ & $\begin{array}{r}13,3 \\
86,7 \\
\end{array}$ & $\begin{array}{c}0 \\
15 \\
\end{array}$ & $\begin{array}{c}0 \\
100 \\
\end{array}$ \\
\hline $\begin{array}{l}\text { Gosto da maioria dos meus professores } \\
\text { Sim } \\
\text { Não }\end{array}$ & $\begin{array}{l}13 \\
02 \\
\end{array}$ & $\begin{array}{l}86,7 \\
13,3 \\
\end{array}$ & $\begin{array}{l}10 \\
05 \\
\end{array}$ & $\begin{array}{l}66,7 \\
33,3 \\
\end{array}$ \\
\hline $\begin{array}{l}\text { Posso contar com meus professores } \\
\text { Sim } \\
\text { Não }\end{array}$ & $\begin{array}{l}11 \\
04\end{array}$ & $\begin{array}{l}73,3 \\
26,7\end{array}$ & $\begin{array}{l}11 \\
04\end{array}$ & $\begin{array}{l}73,3 \\
26,7\end{array}$ \\
\hline $\begin{array}{l}\text { Posso contar com a equipe técnica da escola } \\
\text { Sim } \\
\text { Não }\end{array}$ & $\begin{array}{l}14 \\
01\end{array}$ & $\begin{array}{c}93,3 \\
6,7\end{array}$ & $\begin{array}{l}10 \\
05\end{array}$ & $\begin{array}{l}66,7 \\
33,3\end{array}$ \\
\hline $\begin{array}{l}\text { Parou de estudar para trabalhar } \\
\text { Sim } \\
\text { Não }\end{array}$ & $\begin{array}{c}0 \\
15 \\
\end{array}$ & $\begin{array}{c}0 \\
100 \\
\end{array}$ & $\begin{array}{c}0 \\
15 \\
\end{array}$ & $\begin{array}{c}0 \\
100 \\
\end{array}$ \\
\hline $\begin{array}{l}\text { Situação de trabalho } \\
\text { Nunca trabalhou } \\
\text { Já trabalhou, mas não no momento } \\
\text { Trabalha } \\
\text { Busca trabalho }\end{array}$ & $\begin{array}{c}09 \\
05 \\
0 \\
01\end{array}$ & $\begin{array}{c}60,0 \\
33,3 \\
0 \\
6,7 \\
\end{array}$ & $\begin{array}{l}04 \\
08 \\
02 \\
01\end{array}$ & $\begin{array}{r}26,7 \\
53,3 \\
13,3 \\
6,7 \\
\end{array}$ \\
\hline $\begin{array}{l}\text { Renda (salário mínimo) } \\
\text { Até } 1 \text { salário } \\
1 \text { a } 3 \\
\text { Não sabem } \\
\end{array}$ & $\begin{array}{c}03 \\
0 \\
12 \\
\end{array}$ & $\begin{array}{c}20,0 \\
0 \\
80,0 \\
\end{array}$ & $\begin{array}{l}02 \\
11 \\
02 \\
\end{array}$ & $\begin{array}{l}13,3 \\
73,3 \\
13,3 \\
\end{array}$ \\
\hline $\begin{array}{l}\text { A família recebe auxílio/bolsa } \\
\text { Sim } \\
\text { Não }\end{array}$ & $\begin{array}{l}08 \\
07 \\
\end{array}$ & $\begin{array}{l}53,3 \\
46,7 \\
\end{array}$ & $\begin{array}{l}09 \\
06 \\
\end{array}$ & $\begin{array}{l}60,0 \\
40,0 \\
\end{array}$ \\
\hline $\begin{array}{l}\text { Práticas de lazer } \\
\text { Ficar em casa, assistir TV, internet e ler } \\
\text { Passear, assistir TV, cinema e praticar esporte }\end{array}$ & $\begin{array}{l}04 \\
11\end{array}$ & $\begin{array}{l}26,7 \\
73,3\end{array}$ & $\begin{array}{c}11 \\
4\end{array}$ & $\begin{array}{l}73,3 \\
26,7\end{array}$ \\
\hline
\end{tabular}

Fonte: Pesquisa de campo, 2016.

\section{CONSIDERaÇões FINAIS}

Ao analisar as teias de interação de jovens com escolas do ensino médio da cidade de Parnaíba, Estado do Piauí, pode-se observar que essas teias derivam características que 
assumem as continuidades e mudanças para a sua conexão com figurações sociais, especificamente relacionadas às (re)construídas pelas ações dos sujeitos diante dos fatores objetivos das inter-relações sociais, econômicas, políticas e culturais, que se manifestam por meio dos fatores subjetivos, como confiança, afeto e respeito pela condição juvenil.

Os jovens deste artigo, apesar de representar uma aproximação com a figuração escola, vivenciam os dilemas relacionados em assumir a condição juvenil típica da sociedade moderna capitalista, principalmente porque essa contradiz os elementos que circunscrevem suas teias de interação. A saber, por exemplo, a maioria dos estudantes deste estudo está desempregada, mas busca um emprego, e isso desperta questões que versam a sua permanência no âmbito escolar ao conseguirem um trabalho formal e/ou assumirem responsabilidades maiores.

A perspectiva teórica não poderia ser outra senão aquela que oferecesse ferramentas analíticas ao entendimento de processos que compreendam a reprodução social da condição juvenil nas escolas do Ensino Médio, mas com reconhecimento do caráter fragmentador das ações que se poderia chamar de diferenciador da multiplicidade delas, principalmente porque os sujeitos se (des)conectam por meio de outras figurações sociais.

Portanto, ao trazer escolas do Ensino Médio como ponto de referência para traçar a relação de jovens em suas teias de interações sociais, possibilita-se enxergar alguns traços de suas trajetórias de seus modos de vida nas várias figurações que são construídas de forma contínua ou descontínua como a escola, família, trabalho, amigos e lazer. Mais do que isso, a partir das vivências dos jovens é possível reconhecer os diferentes saberes que podem ser explorados dentro da escola e trabalhados por professores de diferentes áreas, para uma educação multicultural/intercultural.

\section{REFERÊNCIAS}

ABRAMO, H. W. Condição Juvenil no Brasil contemporâneo. In: ABRAMO, Helena W.; BRANCO, Pedro Paulo Martoni (Org.). Retratos da juventude brasileira. São Paulo: Fundação Perseu Abramo, 2005.

ABRAMOVAY, M.; CASTRO, M. G. Ensino médio: múltiplas vozes. UNESCO, 2003.

BERGER, P.; BERGER, B. Socialização: como ser membro da sociedade. In: FORACCHI, M. M.; MARTINS, J. S (Orgs.). Sociologia e sociedade. Rio de Janeiro: LTC, 1978.

BRANDÃO, C. R. Casa de Escola: Cultura Camponesa e Educação Rural. Campinas: Papirus, 1983.

CARA, D. T.; SILVA, D. M.; PAPA, F. de C. Política Nacional de Juventude: diretrizes e perspectivas, 2006.

CARRANO, P. C. R. Os jovens e a cidade. Identidades e práticas culturais em Angra de tantos reis e rainhas. Rio de Janeiro: Relume Dumará/FAPERJ, 2002.

. BRENNER, A. K. Os sentidos da presença dos jovens no Ensino Médio: represen- 
tações da escola em três filmes de estudantes. Educação \& Sociedade (Impresso), v. 35, p. 1.223-1.240, 2014.

CARRANO, P. C. R.; DAYRELL, J. Formação de professores do ensino médio, etapa I - caderno II: o jovem como sujeito do ensino médio / Ministério da Educação, Secretaria de Educação Básica. Curitiba: UFPR/Setor de Educação, 2013.

DAYRELL, J. O projeto de vida é a ação do indivíduo de escolher um dentre os futuros possíveis, transformando os desejos e as fantasias em objetivos a serem perseguidos. In: Projeto de Vida - Como os jovens brasileiros constroem no presente suas perspectivas de futuro. Revista Onda Jovem, São Paulo, ano 1, n. 1, mar./jun. 2005.

. O jovem como sujeito social. Revista Brasileira de Educação. Rio de Janeiro, v. 5/6, n. 24, p. 40-52, 2003.

. O Ensino Médio no Brasil e seus desafios: o que dizem os jovens sobre o processo de exclusão escolar. In: Linguagens, Educação e Sociedade: Revista do Programa de Pós-Graduação em educação da UFPI/ Universidade Federal do Piauí/ Centro de ciências da Educação, ano 18, Edição Especial Dossiê Educação e Juventudes. Teresina: EDUFPI, 2013, 353p. 77-101p.

ELIAS, Norbert. A sociedade dos indivíduos. Rio de Janeiro: Jorge Zahar Ed., 1994a.

. O processo civilizador. Vol. I. Uma história dos costumes. Rio de Janeiro: Jorge Zahar Ed., 1994b.

. SCOTSON John. Os Estabelecidos e os Outsiders. Rio de Janeiro: Jorge Zahar Ed., 2000.

GROPPO, L. A. Juventude: Ensaios sobre Sociologia e História das Juventudes Modernas. Rio de Janeiro: DIFEL, 2000.

MELO, S. P.; SANTANA, J. F. O perfil sociocultural de jovens que evadiram de uma escola do Ensino Médio de Parnaíba-PI. Relatório de pesquisa (mimeo), 2017, 76p.

MELUCCI, A. O jogo do eu: a mudança de si mesmo na sociedade globalizada. Rio de Janeiro: Editora Feltrinelli, 1992.

NOSELLA, P. Compromisso político e competência técnica: 20 anos depois. Educação \& Sociedade, v. 26, n. 90, p. 223-238, 2005.

PAIS, J. M. Culturas juvenis. Lisboa: Imprensa Nacional Casa da Moeda, 1993.

. Tachos e Biscates: Jovens, Trabalho e Futuro. Porto: Âmbar, 2001.

PEREGRINO, M.; CARRANO, P. C. Escolas e jovens que se habitam: desafios cotidianos e de fins de semana. Observatório Jovem. Disponível em: $<$ http://www.iets.org $>$. Acesso em: 22 out. 2016.

RICHARDSON, R. J. Pesquisa social: métodos e técnicas. São Paulo: Atlas, 1989. 
SOUSA, S. Z.; OLIVEIRA, R. P. de. Ensino Médio noturno: democratização e diversidade. Educar em Revista, n. 31, 2008.

SPOSITO, M. P. Algumas reflexões e muitas indagações sobre as relações entre juventude e escola no Brasil. Retratos da juventude brasileira: análises de uma pesquisa nacional, p. 87-128, 2005.

WAUTIER, A. M. et al. Para uma sociologia da experiência. Uma leitura contemporânea: François Dubet. Sociologias, v. 5, n. 9, 2003.

Submetido em: 20-8-2017

Aceito em:6-11-2017 